\title{
The Seasonal Occurrence of the Snoutbeetle, Phlyctinus callosus Boheman (Coleoptera: Curculionidae) on Vines in the Robertson Area.
}

\section{A. SCHWARTZ}

Viticultural and Oenological Research Institute, Private Bag X5026, 7600 Stellenbosch, Republic of South Africa

Date Submitted: November 1984

Date Accepted: December 1984

Keywords: Phlyctinus callosus, Snoutbeetle, Grapevine

\begin{abstract}
Snoutbeetles have been known as a pest in vineyards for many years (Whitehead, 1961a). Five species have been identified as economically important. As a rule only one, two or three of the species are to be found in the same area. A similar type of damage is caused by the various species of snoutbeetles but differences in the seasonal occurrence are important as regards the critical time for the application of chemical control measures. This information is available for four of the wine producing areas of the Western Cape, one of the exceptions being Robertson (Whitehead, 1961a; 1961b).
\end{abstract}

\section{PROCEDURE}

In the present study observations were carried out in a trellised 15 year old Chenin blanc vineyard. Insecticide sprays were withheld from the vineyard during the period of study, but a standard VORI disease control program had to be followed. The following method of assessing snoutbeetle presence was used : a strip of corrugated card- board, $100 \mathrm{~mm}$ wide, was fastened at a height of $\pm 400 \mathrm{~mm}$ to each of 30 stems, which were randomly selected in the vineyard. The snoutbeetles sheltered under the cardboard strips at night and could be counted during the day by removing the strips. Observations were made at intervals of two weeks from the beginning of October until the middle of February, when the crop was harvested. After this assessments were made once a month.

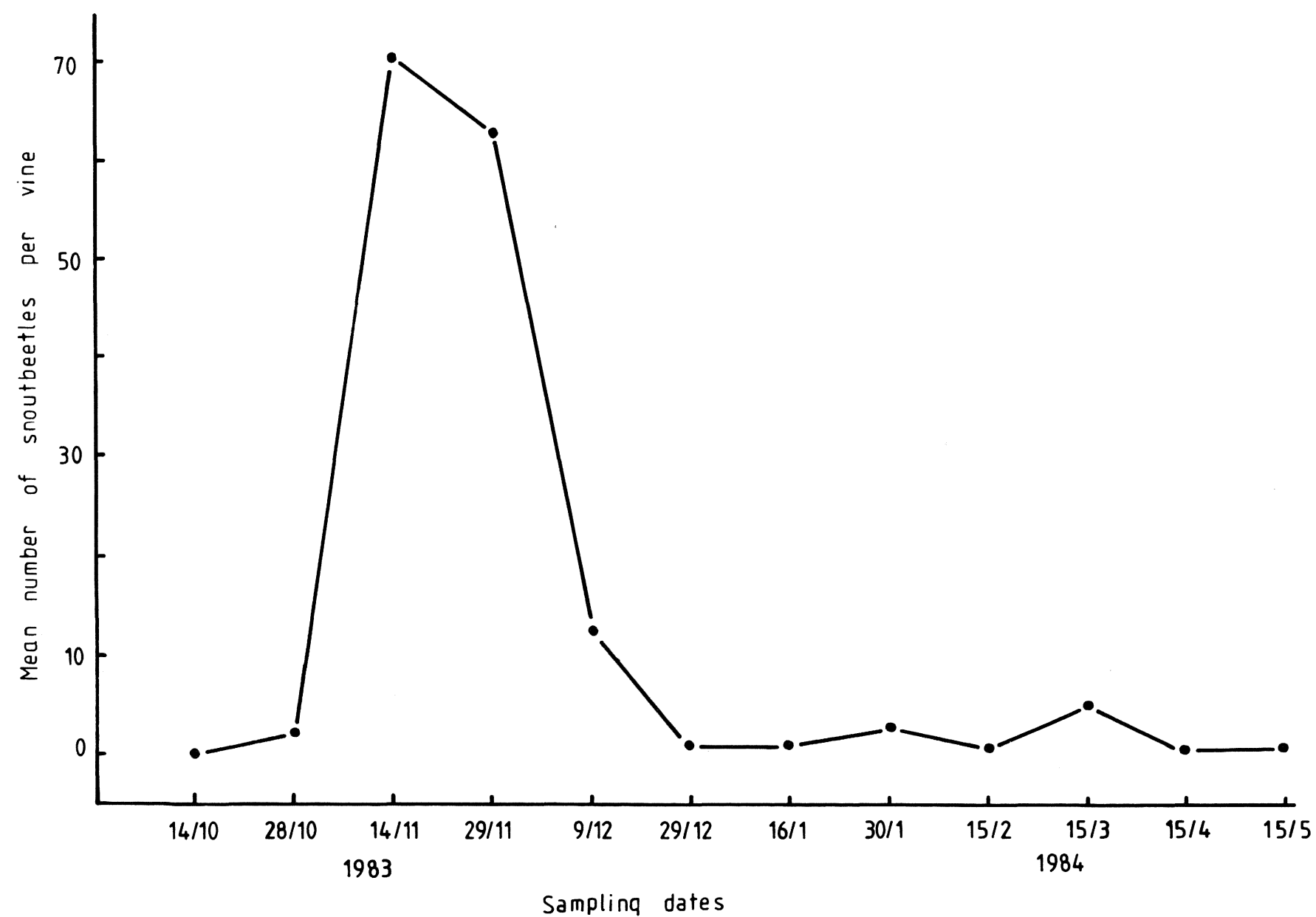

FIG. 1

Seasonal occurrence of Phlyctinus callosus on Chenin blanc vines in the Robertson area. 


\section{RESULTS}

Identification of specimens showed that only Phlyctinus callosus Boheman was involved. The seasonal incidence of $P$. callosus is illustrated in Fig. 1. From these results it is apparant that the emergence of the adult beetles from the soil commenced at the end of October and that the population reached a maximum during the middle of November. At the end of November the snoutbeetle numbers were still high but decreased considerably during the beginning of December. Subsequently the population dwindled even further reaching a very low level during the greater part of January. The population remained low until the middle of February when the crop was harvested.

\section{CONCLUSIONS}

The above pattern of snoutbeetle occurrence shows similarity to that demonstrated for P. callosus in Stellen- bosch (Whitehead, 1961b), i.e. for the period extending from October to the middle of May. In vineyards the early season build-up of adult snoutbeetles is very important as this is the time when the most severe damage is caused to shoots, leaves and young bunches. The population pattern observed during the present study thus has a bearing on the timing of control measures for this area. It is imperative that growers be on the alert as from the end of October.

\section{LITERATURE CITED}

WHITEHEAD, V. B. 1961a. Vine snoutbeetles. Some facts about them and control. Decid. Fruit. Grow. 11(9), 261-263.

WHITEHEAD, V. B., 1961 b.Report on the distribution and occurrence of vine snoutbeetles in the Stellenbosch, Somerset West, Paarl and Wellington areas, 1958 to 1961 . Unpublished report FR 24/7, Fruit and Food Technology Research Institute, Private Bag X5013, 7600 Stellenbosch, Republic of South Africa. 